\title{
Catalysis of Methanol-Air Mixture Using Platinum Nanoparticles for Microscale Combustion
}

\author{
James R. Applegate, ${ }^{1}$ Howard Pearlman, ${ }^{2}$ and Smitesh D. Bakrania ${ }^{1}$ \\ ${ }^{1}$ Mechanical Engineering Department, Rowan University, 201 Mullica Hill Road, Glassboro, NJ 08028, USA \\ ${ }^{2}$ Advanced Cooling Technologies, Inc., 1046 New Holland Avenue, Lancaster, PA 17601, USA
}

Correspondence should be addressed to Smitesh D. Bakrania, bakrania@rowan.edu

Received 24 February 2012; Accepted 10 April 2012

Academic Editor: Grégory Guisbiers

Copyright ( 2012 James R. Applegate et al. This is an open access article distributed under the Creative Commons Attribution License, which permits unrestricted use, distribution, and reproduction in any medium, provided the original work is properly cited.

\begin{abstract}
High surface area, active catalysts containing dispersed catalytic platinum nanoparticles $\left(d_{p} \sim 11.6 \mathrm{~nm}\right)$ on a cordierite substrate were fabricated and characterized using TEM, XRD, and SEM. The catalyst activity was evaluated for methanol oxidation. Experimental results were obtained in a miniature-scale continuous flow reactor. Subsequent studies on the effect of catalyst loading and reactor flow parameters are reported. Repeat tests were performed to assess the stability of the catalyst and the extent of deactivation, if any, that occurred due to restructuring and sintering of the particles. SEM characterization studies performed on the postreaction catalysts following repeat tests at reasonably high operating temperatures $\left(\sim 500^{\circ} \mathrm{C}\right.$ corresponding to $\sim 0.3 T_{m}$ for bulk platinum) showed evidence of sintering, yet the associated loss of surface area had minimal effect on the overall catalyst activity, as determined from bulk temperature measurements. The potential application of this work for improving catalytic devices including microscale reactors is also briefly discussed.
\end{abstract}

\section{Introduction}

Catalytic nanoparticles offer a substantial increase in surface area to volume ratio relative to their bulk counterparts and are important in a variety of energy-related applications and chemical processes. Platinum nanoparticles, for example, are embedded in the membranes of proton exchange membrane (PEM) fuel cells [1-3] and used in other systems including micropower generation $[4,5]$, automotive exhaust cleanup [6], and oxidation of volatile organic compounds (VOCs) [7]. Platinum nanoparticles are also being explored for use as radiosensitizers and new medical applications including targeted cancer treatments [8]. Regarding the use of nanosized catalysts, their high surface energy is responsible for their high catalyst activity [9-12]. Increased catalyst activity offers the potential to reduce the amount of catalyst needed and reduce the operating temperature of the catalyst. In turn, knowing that the sintering temperature of nanoparticles is size dependent, sintering may be less of an issue for catalysts that operate at low temperature, yet special consideration must be given before such a conclusion can be drawn.
Typically, the sintering temperature is $0.2-0.3$ of the melting temperature $T_{m}$ for nanoparticles and $0.5-0.6 T_{m}$ for larger size particles $[10,13]$.

In this study, platinum nanoparticles are synthesized, dispersed on a cordierite substrate, tested in a continuous flow reactor, and characterized before and after use in the reactor. The results obtained in this fundamental study will also potentially be used to enhance the performance and sustain chemical reaction in a microscale combustor. In the past 10 years, much research has been performed on microscale combustion aimed at developing a small-scale generator that can replace batteries and rapidly be recharged by simply adding fuel [4, 4-17]. Since hydrocarbon fuels have an energy density of $\sim 40 \mathrm{MJ} / \mathrm{kg}$, a device having an overall systemlevel efficiency (chemical-to-electrical energy) in excess of $1 \%$ would have a comparable energy density to the stateof-the-art Li-ion batteries $(\sim 0.5 \mathrm{MJ} / \mathrm{kg})[18,19]$. Sustaining combustion, however, in small-scale channels necessitates the use of catalysts or advanced heat recirculating strategies, otherwise conduction heat loss owed to the high surface area of the device exceeds the heat generation rate $(\sim$ volume of 
the device), and self-sustained operation cannot be achieved [20-23]. In this application, it is envisioned that nanosized platinum catalysts can be used to sustain combustion at low operating temperatures, alleviating concerns with quenching.

Platinum nanoparticles have been previously demonstrated to self-ignite small alcohols, notably methanol-air, at room temperature and their reactivity is particle size dependent [24]. Nominal particle sizes, as large as $500 \mathrm{~nm}$, have been tested with methanol-air premixtures and nearly complete oxidation was achieved without the need to preheat the catalyst $[24,25]$. Additionally, size-dependent catalyst activity was also established, with increased activity observed for smaller nanoparticles $[2,25]$. Beck and coworkers [11] have further shown that peak catalytic activity exists for $2 \mathrm{~nm}$ Pt nanoparticles during methane oxidation, explained by the competing effect of oxidized and metallic platinum species on catalyst activity [11]. Coalescence or sintering, however, becomes major concerns using nanoparticles since they are exposed to relatively high temperatures $[10,26,27]$. To improve stability and hinder degradation of catalyst, several strategies are pursued including alloying and composite structures for improved sintering resistance [27-29]. While such modified Pt catalysts show appreciable success, pure platinum nanoparticles remain attractive due to their high catalytic activity. Pt nanoparticles therefore warrant further investigation.

Several studies have reported synthesis techniques for Pt and other metal nanoparticles, yet systematic studies aimed at evaluating their initial and long-term catalyst activity in real-world systems are limited. This study therefore focussed on repeated catalytic cycling from room temperature ignition to stable catalysis temperatures and its influence on the $\mathrm{Pt}$ catalyst nanoparticles. The outcomes are directly applicable to development of devices that integrate microscale combustion as an energy source.

\section{Experimental}

2.1. Material Synthesis. Platinum nanoparticles were synthesized via a colloidal synthesis technique described by Bonet, et al. [30]. Briefly, $45 \mathrm{~mL}$ of ethylene glycol (EG, 99.8\% purity, Sigma Aldrich) was heated up to $150^{\circ} \mathrm{C}$ in a reflux reactor. Hexachloroplatinic acid $(500 \mathrm{mg})\left(\mathrm{H}_{2} \mathrm{PtCl}_{6}, \mathrm{ACS}\right.$ reagent grade, Sigma Aldrich) was first dissolved in $5 \mathrm{~mL}$ of EG, at which time, the solution was then combined with the remaining heated EG. Then, $100 \mathrm{mg}$ of polyvinylpyrrolidone (PVP, M.W. 29,000, Sigma Aldrich) was dissolved in $25 \mathrm{~mL}$ of EG and added to the heated solution with the aid of a syringe pump at a rate of $1.5 \mathrm{~mL} / \mathrm{min}$. The solution was maintained at $150^{\circ} \mathrm{C}$ for a period of one hour.

To clean the Pt nanoparticles in solution, a centrifuge tube containing $25 \mathrm{~mL}$ of methanol (99.8\%, Sigma Aldrich) was added to $5 \mathrm{~mL}$ of the EG-PVP-Pt nanoparticle solution. The solution was agitated by hand for one minute and then centrifuged for $2 \mathrm{~min}$ at $3,000 \mathrm{rpm}$. After pouring off the supernatant, $25 \mathrm{~mL}$ of distilled water was substituted. The precipitate was agitated mechanically until a suspension of $\mathrm{Pt}$ nanoparticles was achieved. The resulting solution was then centrifuged for another $2 \mathrm{~min}$ at 3,000 rpm. The supernatant was again discarded and replaced with $5 \mathrm{~mL}$ of distilled water. The precipitate was agitated mechanically and sonicated for one minute.

2.2. Substrate Preparation. The substrate for the nanoparticles was an extruded cordierite monolith (900 cells per square inch, Corning Inc.). The monolith had square channels with a width of $0.85 \mathrm{~mm}$ and wall thickness of $0.05 \mathrm{~mm}$. The overall dimensions of the monoliths were $19 \mathrm{~mm}$ in length and the cross section contained 14 cells; the cross-sectional shape was octagonal and the maximum dimension across the crosssection was $13.5 \mathrm{~mm}$.

The Pt nanoparticles, synthesized and suspended in solution, were deposited on the substrates using a drawcoat method. In particular, the Pt colloidal suspension was drawn through the open cells of the substrate, which was vertically mounted, using a $10 \mathrm{~mL}$ syringe connected directly to the substrate using a flexible clay coupling. The substrates were subsequently placed horizontally (with respect to the channel length) in an open petridish and dried at ambient conditions. Using this technique, a single dispersion of $\mathrm{Pt}$ nanoparticles was deposited on the bottom wall (base) of the channel. To coat adjacent walls, the substrate was rotated $90^{\circ}, 180^{\circ}$, and $270^{\circ}$ and a second, third, and forth application of the Pt solution was applied, each done in succession and allowed to dry prior to application of each sequential coat. Molar conversion calculations indicated that approximately $10 \mathrm{mg}$ of Pt particles were deposited per deposition step. Consequently, mass loading studies described later refer to the number of coatings during this step of substrate preparation.

2.3. Catalysis Experiments. The catalysts were tested in a continuous flow reactor fabricated with an aluminum housing as schematically shown in Figure 1. The reactor was $55.4 \mathrm{~mm}$ long and $20.3 \mathrm{~mm}$ in external diameter. Quartz wool was used as a filler in the gap between the reactor and the substrate so not to allow the gases to take a lower pressure drop bypass and flow through the honeycomb catalyst. The reactor inlet was designed to enable different catalyst materials to easily be inserted and removed. The inlet to the portion of the reactor containing the catalyst was $14.3 \mathrm{~mm}$ (KF-16 flange), which was tapered to a $1 / 4-20 \mathrm{NPT}$ fitting though which the reactants were introduced.

The experiments were conducted by bubbling compressed air (99.9\% purity, Air Gas) through a methanol reservoir (99.8\% purity, Sigma Aldrich) at a metered flow rate of $200-1100 \mathrm{~mL} / \mathrm{min}$ using a $30 \mathrm{~mL}$ glass bubbler. Calculated velocities through the substrate channels ranged from $2.3 \mathrm{~cm} / \mathrm{s}$ to $12.8 \mathrm{~cm} / \mathrm{s}$. The methanol saturated air flowed through the Pt-coated substrate channels and the products exited from the reactor. A coated $0.5 \mathrm{~mm}$ diameter $\mathrm{K}$ type thermocouple (KMTXL-020G, Omega) was cemented $7.6 \mathrm{~mm}$ from the exit of the center channel using high temperature cement (Omega) to monitor the bulk temperature of the catalyst substrate at the center. Temperature measurements were acquired at $10 \mathrm{~Hz}$ using a LabView DAQ system. External reactor temperatures were obtained 


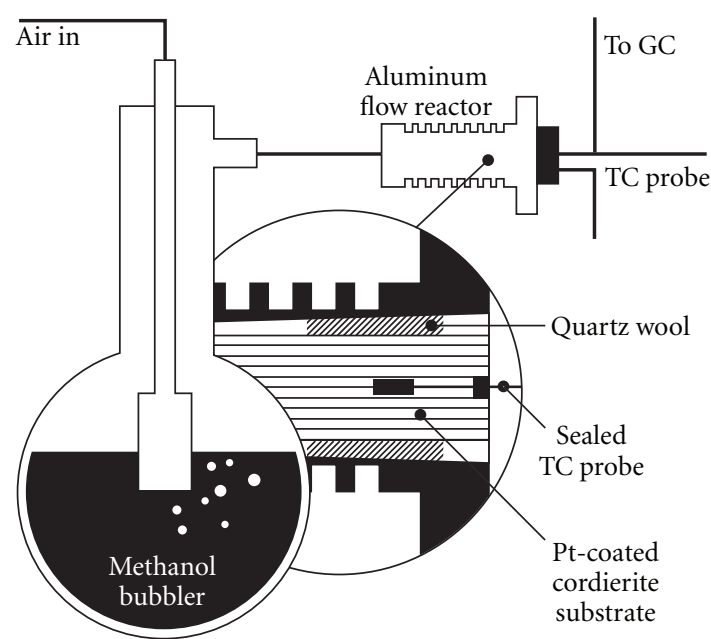

Figure 1: The experimental setup for Pt nanoparticle catalysis of methanol-air mixture. The inset provides details of the reactor and the catalyst substrate with an embedded sealed thermocouple.

by placing a thermocouple on the surface of the aluminum reactor.

2.4. Material Characterization. The nanoparticles were analyzed using an X-ray diffractometer (XRD, PANalytical 9430), a transmission electron microscope (TEM, Hitachi $\mathrm{H}-600 \mathrm{ABi}$ ), and a scanning electron microscope (SEM, Zeiss Supra 50VP). XRD reflection scans were obtained by dispersing $\mathrm{Pt}$ nanoparticles on a glass slide and analyzed at a scan rate of $2 \% \mathrm{~min}$ using continuous scan mode and a $\operatorname{CuK}_{\alpha}$ source $(\lambda=1.5405 \AA)$. Scherrer analysis was used to obtained average crystallite size. TEM samples were prepared by placing a drop-coat of the as-synthesized $\mathrm{Pt}$ colloidal solution on a $3 \mathrm{~mm}$ carbon-coated copper grid. A semiautomated program described elsewhere [31] was used to analyze particle size distributions. The deposited catalysts were analyzed on an SEM by removing fragments of pre- and post-catalysis substrate channel walls and placing them on a piece of carbon tape for imaging.

\section{Results and Discussion}

The measured temperature of the reactant gases at the inlet was $22^{\circ} \mathrm{C}$. Based on methanol vapor pressure at the measured temperature, the saturated methanol-air mixture yields an effective equivalence ratio $\phi$ of 1.18. However, previous work by $\mathrm{Ma}$ and coworkers [25] with identical methanol delivery system indicates that the equivalence ratio is a weak function of the air inlet velocity. Considering the flow rates used for this study, a slightly fuel lean mixture $(\phi=0.9-0.95)$ of methanol-air was being introduced to the catalyst substrate.

Figure 2 displays the temperature history for a typical catalysis run lasting three hours. It should be noted that the temperature here indicates the bulk substrate temperature and not the Pt catalyst temperature; it is possible to have higher localized temperatures on the nanoparticles. The results presented in Figure 2 were generated using a substrate

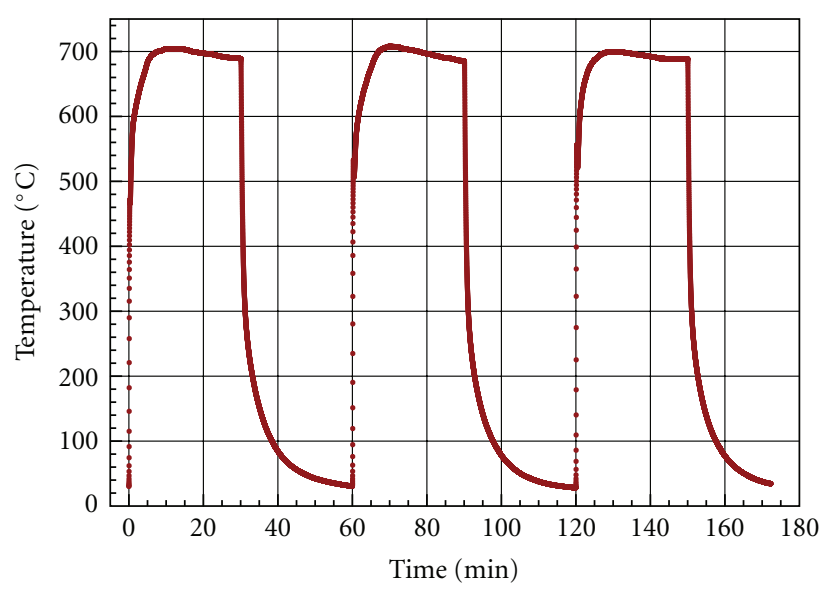

Figure 2: Temperature versus time graph of a substrate with four coatings of Pt nanoparticles demonstrating room temperature ignition and highly repeatable catalytic cycling. A constant flow rate of $600 \mathrm{~mL} / \mathrm{min}$ was maintained.

with four Pt-coated sides and a nominal flow rate of $600 \mathrm{~mL} / \mathrm{min}$. The introduction of methanol-saturated air into the reactor produces a simultaneous rise in substrate temperature that peaks at $700^{\circ} \mathrm{C}$. Figure 2 , therefore, demonstrates room temperature ignition of methanol-air mixture due to the presence of Pt nanoparticles. When the flow of methanol-air mixture was halted, the substrate temperature approached room temperature within 30 minutes. After a total of an hour, a second catalysis cycle began. The temperature at the exterior of the reactor was approximately $200-300^{\circ} \mathrm{C}$ lower than the substrate temperature suggesting notable heat loss to the ambient air through the reactor walls. The subsequent cycles in Figure 2 represent repeatable catalysis runs highlighting the self-ignition and nominally stable peak temperatures using Pt nanoparticles.

Identical results were obtained for all samples prepared using the same synthesis procedure; that is, the results presented in Figure 2 were reproducible with respect to ignition and stable high temperatures. It should be noted that even though the catalysis temperatures demonstrate a slight downward drift in temperatures, the overall behavior was repeatable. The catalysis cycling on a single catalysis sample was repeatable for over 30 cycles (with each cycle lasting $1 \mathrm{hr}$ ) without any sign of catalyst degradation. To explore the drift in stable temperature a prolonged single cycle experiment was conducted for six hours. Figure 3 shows how a stable temperature of around $450^{\circ} \mathrm{C}$ is obtained beyond the initial peak in exothermicity. The stable temperature is maintained for over three hours before instabilities in temperature are observed. The substrate selected for the stability study had two opposite sides of the channel coated with $\mathrm{Pt}$ nanoparticles. It is assumed that the prolonged exposure to the high temperature eventually yields microstructural and hence surface area changes that in turn influence the catalytic stable temperatures. The extended stability tests beyond the test presented were limited by the bubbler capacity. The catalyst substrates involved in the standard cycling tests were 


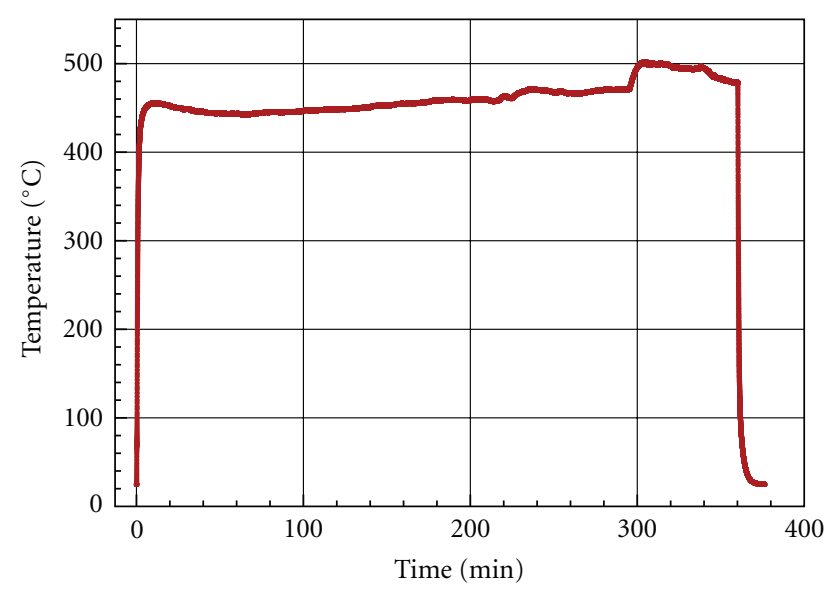

Figure 3: Temperature history of a substrate with two opposite channel walls coated with Pt nanoparticles experiencing catalysis reaction over prolonged period of time. A constant flow rate of $400 \mathrm{~mL} / \mathrm{min}$ was maintained.

observed to be reusable as long as the period between two experimental runs did not exceed 48 hours. It is assumed that the catalyst material experiences poisoning or degradation when exposed to ambient air for prolonged period of time, as suggested by other researchers [24, 27, 32].

Extensive work has been performed in the field of nanoparticle catalysis on preventing degradation of these nanometer sized particles when exposed to relatively high temperatures. The degradation occurs due to the high temperature sintering or coalescence of metallic particles in the nanometer size range $[9-11,25,27]$. To counter this effect of high temperatures, researchers have explored supported Pt nanoparticles to prevent significant coalescence and therefore improve stability with some notable success $[28,29]$. On the other hand, the highly repeatable nature of Pt nanoparticle catalysis behavior observed for the current study has been rarely reported. Material characterization was performed to assess the state of the catalyst materials before and after the catalysis runs.

3.1. Catalyst Material Characterization. The synthesized Pt nanoparticles when analyzed for crystallite sizes using XRD yielded an average of $d_{\mathrm{XRD}}=8.9 \mathrm{~nm}$. The same particles when observed under a TEM showed discrete unsintered spherical nanoparticles as depicted in Figure 4(a). It should be noted that the agglomerated nature of the particles seen in the TEM was potentially a result of the grid sample preparation which was analogous to the catalyst substrate preparation method. In other words, the agglomerated nature of the particles in the TEM images can be used as a representative sample of how the particles would look on the cordierite substrate. TEM image analysis of the nearly 200 particles produced an average particle size $d_{p}$ of $11.6 \mathrm{~nm}$. Figure 4(c) provides the output of the semiautomated image analysis showing a Pt nanoparticle distribution ranging from 7 to $20 \mathrm{~nm}$. Both $d_{\mathrm{XRD}}$ and $d_{p}$ were in good agreement considering the biases involved with the two approaches.
The as-deposited nanoparticle coatings were investigated using SEM imaging. Figures 5(a) and 5(b) display precatalysis SEM images of the substrate wall fragment. Due to the limited resolving power offered by the SEM, it is difficult to distinguish individual Pt nanoparticles near the $10 \mathrm{~nm}$ size range; however it is clear from the images that significant catalyst coverage was achieved. Porous Pt-aggregated films were observed on the cordierite substrate represented by micron sized smooth structures in the background. The aggregated films observed using SEM were similar in structure to the particles observed using the TEM in Figure 4(a). The films of particles were identified as elemental platinum using XEDS mapping.

In order to investigate the effect of catalysis and the resulting high combustion temperatures on Pt nanoparticles, fragments of a postcatalysis substrate sample were analyzed using the SEM. Figure 5(c) shows SEM images of a substrate coated on four sides that experienced a peak temperature of $500^{\circ} \mathrm{C}$ for two cycles. As observed from the sample images, the overall structure of $\mathrm{Pt}$ films seen in the precatalysis images is still present, however the structure is noticeably less porous and coalesced in nature. The same Pt nanoparticles that subsequently experienced $1120^{\circ} \mathrm{C}$ peak temperature yielded significantly coalesced spherical particles shown in Figure 5(d). XEDS analysis confirmed the bright spherical particles as the Pt nanoparticles in Figure 5(d). Image analysis of over 500 of the fully coalesced particles yielded an average particle size of $88 \mathrm{~nm}$. Assuming the clusters of adjoined nanoparticles coalesced to yield the larger particles, estimated 600 particles constituted the porous films observed in Figures 5(a)-5(c).

Based on the catalyst structural observations, there is discernible catalyst degradation with respect to coalescence and thus the loss of surface area as a function of stable catalysis temperatures. However, from the catalysis temperature studies (Figure 2) which depict repeatable catalytic cycling of the material, the effect of coalescence is minimal when lowto-moderate operating temperatures (less than $1000^{\circ} \mathrm{C}$ ) are maintained. In other words, the loss in Pt porosity and specific surface area, such as seen in Figure 5(c), demonstrated only minor influence on the reactivity of the catalyst for the conditions and materials tested. Catalyst stability similar to that observed here has been demonstrated before by Karim and coworkers [15] with Pt nanoparticles deposited on anodized alumina substrate. However, the higher operating stable temperatures with the repeatable cycling studies make these results unique and warrant further investigation of operational regimes for this system as required for potential applications in a portable power production device.

3.2. Flow Rate Dependence. To investigate the behavior of the catalyst substrate as a function of methanol-air mixture flow rate, a sample with four sides coated with Pt nanoparticles was tested. Figure 6 shows the dependence of the substrate temperature on volumetric flow rate of the reactants. As the compressed air flow rate was increased from $200 \mathrm{~mL} / \mathrm{min}$ to $1000 \mathrm{~mL} / \mathrm{min}$ in increments of $100 \mathrm{~mL} / \mathrm{min}$, the stable temperature of the substrate increased from $500^{\circ} \mathrm{C}$ to almost $900^{\circ} \mathrm{C}$. These results are in agreement with similar studies 


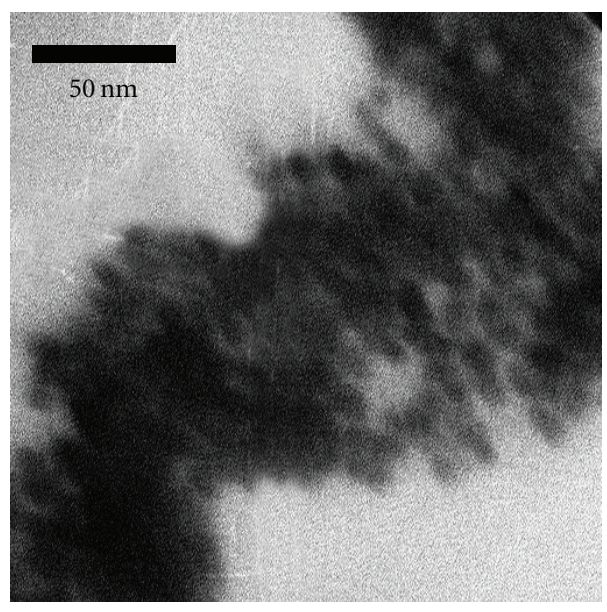

(a)

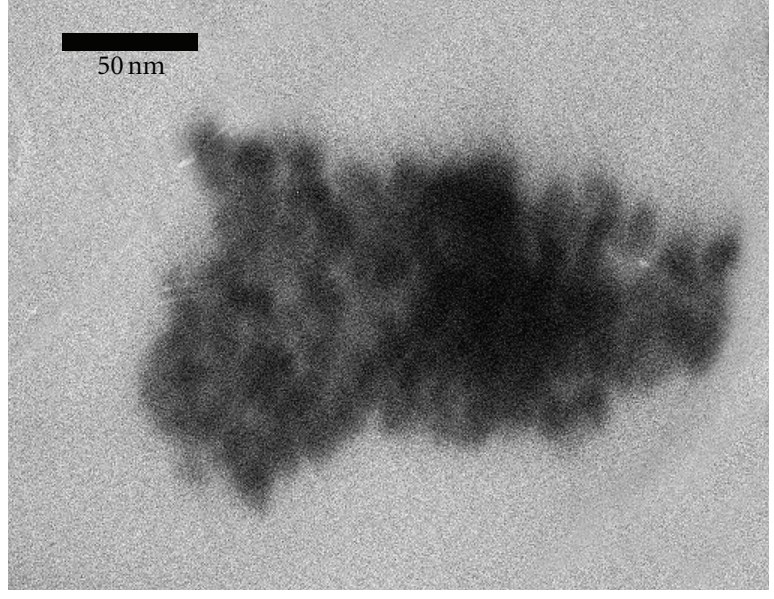

(b)

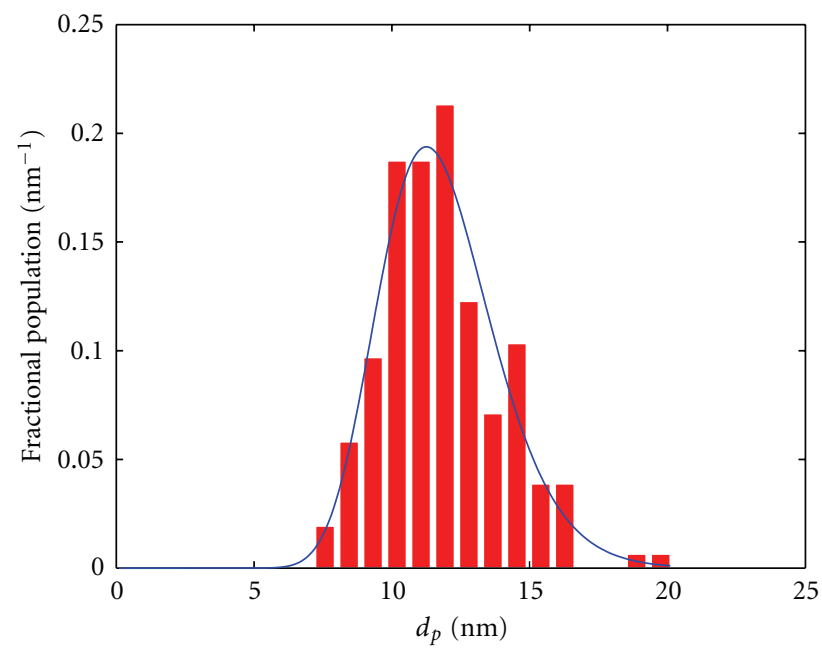

(c)

FIGURe 4: (a) and (b) TEM images of unreacted platinum nanoparticles. (c) Particle distribution plot of Pt nanoparticles analyzed using a semiautomated sizing approach based on TEM images.

that show higher fuel-air flow rate results in higher rate of heat release by the catalysis reaction manifested as an elevated stable temperature $[15,25]$. The diminishing rate of corresponding increase in temperature can be attributed to the saturation of the active catalytic sites leading to incomplete conversion of reactants to products. For stable temperatures beyond $700^{\circ} \mathrm{C}$, an initial peak in temperature appeared before plateauing to the stable temperature. Such behavior was documented by $\mathrm{Ma}$ and coworkers using Pt nanoparticles supported on quartz wool [25]. Beyond $800^{\circ} \mathrm{C}$ however, a rapid spike in temperature emerged that indicated substrate temperature reaching $1100-1150^{\circ} \mathrm{C}$ before returning to the shape of temperature history at lower flow rates. The rapid spikes were observed for compressed air flow rates of greater than $800 \mathrm{~mL} / \mathrm{min}$. While these samples with high flow rates showed repeatable catalytic cycling, their lifespan was dramatically reduced due to catalyst degradation. Samples tested at flow rates greater than
$1000 \mathrm{~mL} / \mathrm{min}$ were unable to demonstrate self-ignition for the second cycle, suggesting significant degradation of the catalyst substrate due to the high temperatures.

3.3. Mass Loading Dependence. A mass loading study was conducted by varying the number of coatings within the channels of the cordierite substrate. Since a single coating was applied to each wall of the square channel, mass loading study involved up to four Pt-coated sides. The mass loading study was carried out at the minimum compressed air flow rate of $200 \mathrm{~mL} / \mathrm{min}$ to maintain low stable temperatures. With the combination of low flow rate and the low mass loading, the single Pt-coated substrate did not ignite at room temperature. Facilitating room temperature ignition required a minimum of two coatings. As seen in Figure 7, the increase in number of Pt-coated sides is accompanied by corresponding increase in stable temperature. Again, the heat release is a function of fuel conversion rate which 


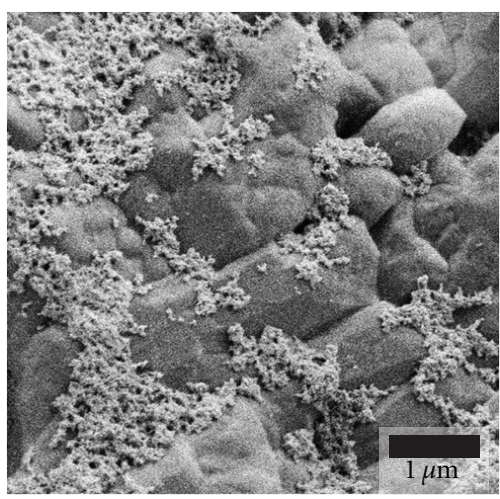

(a)

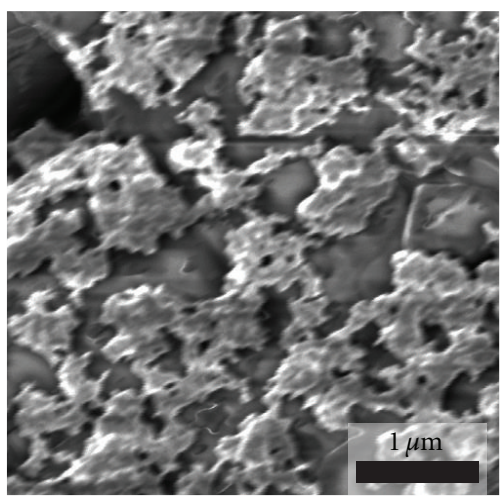

(c)

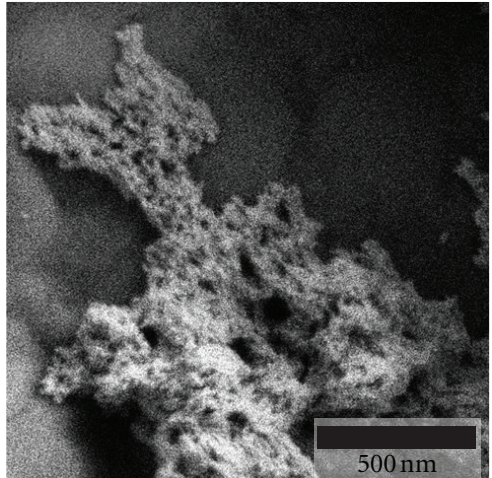

(b)

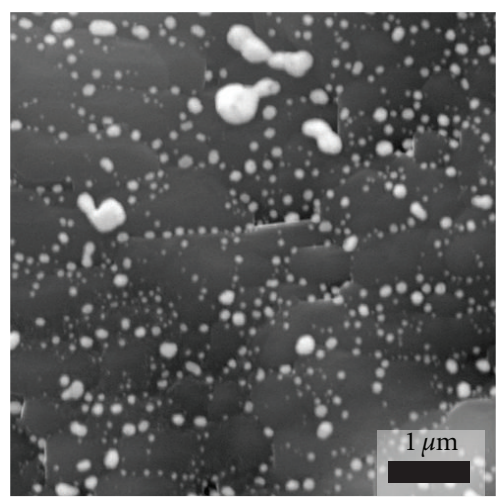

(d)

FIgure 5: (a) and (b) are SEM images of Pt particles deposited on the substrate walls prior to catalysis (precatalysis). (c) Postcatalysis SEM image of Pt nanoparticles with moderate sintering with peak temperatures of $500^{\circ} \mathrm{C}$ after two cycles $(1 \mathrm{hr}$ cycle time). (d) Coalesced spheres of metallic Pt after experiencing peak temperatures of $1120^{\circ} \mathrm{C}$ over 25 cycles.

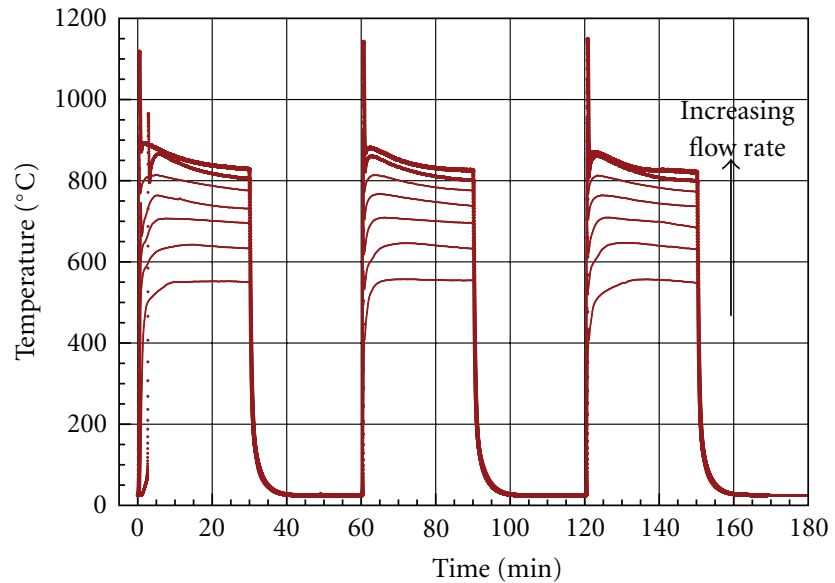

FIGURE 6: Temperature histories for air flow rates ranging from 200 to $1000 \mathrm{~mL} / \mathrm{min}$ with $100 \mathrm{~mL} / \mathrm{min}$ increments. Catalyst substrates with four Pt-coated were sides used in this study.

is dependent on the available active catalytic sites. As the number of coatings increased, the active sites increased driving higher rate of heat released.

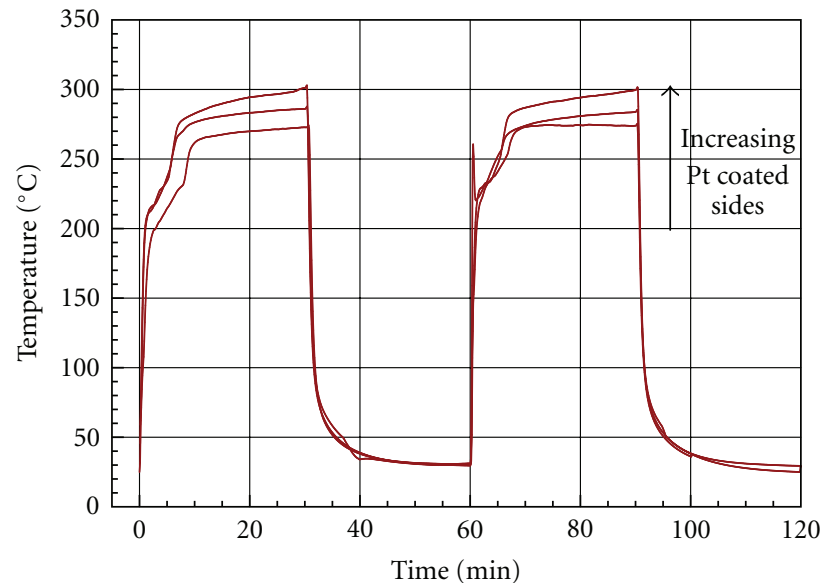

FIGURE 7: Temperature histories for substrates with two, three, and four Pt-coated sides with air flow rate at $200 \mathrm{~mL} / \mathrm{min}$.

3.4. Device Performance Implications. For catalytic microscale combustion applications, typically long residence time channel reactors are employed, such as the swiss-roll type reactor $[4,22]$. Considering the short catalytic substrate 
sample $(19 \mathrm{~mm})$ and the high reactant flow rates (200$1000 \mathrm{~mL} / \mathrm{min}$ ) used here, it is expected that only fractional conversion of the fuel and oxidizer mixture is achieved. Within a device however, the excess methanol fuel can be combusted by extending the catalytic channel to allow longer residence times for the fuel to react. In addition, due to the catalytic stability offered by the cycling approach used here, the peak temperatures of the overall device can be easily controlled by tuning the catalytic cycling to match the thermal requirements of the device. Alternatively, the mass loading study indicated that substrates coated with a single layer of Pt nanoparticles failed to ignite potentially as a result of the low heat generation rate compared to the heat loss to the surroundings. Therefore, strategies used to diminish heat loss in microreactors can significantly reduce the $\mathrm{Pt}$ mass loadings required to sustain combustion. Furthermore, the size-dependent catalytic reactivity of Pt nanoparticles can provide an additional control parameter for targeted device operation conditions and is currently being explored $[11,25]$.

\section{Conclusion}

Platinum nanoparticles have been previously identified as strong candidates for sustaining microscale combustion and have been used for many years in automotive catalytic converters for exhaust gas cleanup. However, their vulnerability to sintering at high combustion temperatures results in a decrease in the catalyst activity and limits the catalyst lifetime. Therefore, the demonstration of repeatable Pt nanoparticle catalysis over numerous cycles in this work is an important step towards achieving controlled catalytic combustion. The cycling studies showed that nanoparticle sintering can be dramatically reduced to cause minimal or negligible change in the activity of the catalyst particles. The flow rate and mass loading studies provided additional insights into operational regimes of a potential microreactor. As next steps, quantitative investigation of the product gases as a function of cycling periods, particle size, and catalyst distribution can provide data necessary to model and design functional efficient microcombustor systems.

\section{Acknowledgments}

The authors would like to acknowledge the support of the National Science Foundation CBET Grant 0755740. The authors would like to thank Rowan University's Materials Research Laboratory for allowing the use of instrumentation.

\section{References}

[1] S. Litster and G. McLean, "PEM fuel cell electrodes," Journal of Power Sources, vol. 130, no. 1-2, pp. 61-76, 2004.

[2] T. Frelink, W. Visscher, and J. A. R. van Veen, "Particle size effect of carbon-supported platinum catalysts for the electrooxidation of methanol," Journal of Electroanalytical Chemistry, vol. 382, no. 1-2, pp. 65-72, 1995.

[3] M. C. Orilall, F. Matsumoto, Q. Zhou et al., "One-pot synthesis of platinum-based nanoparticles incorporated into mesoporous niobium oxide-carbon composites for fuel cell electrodes," Journal of the American Chemical Society, vol. 131, no. 26, pp. 9389-9395, 2009.

[4] Y. Ju and K. Maruta, "Microscale combustion: technology development and fundamental research," Progress in Energy and Combustion Science, vol. 37, no. 6, pp. 669-715, 2011.

[5] A. Mitsos, B. Chachuat, and P. I. Barton, "What is the design objective for portable power generation: efficiency or energy density?" Journal of Power Sources, vol. 164, no. 2, pp. 678-687, 2007.

[6] W. C. Pfefferle and L. D. Pfefferle, "Catalytically stabilized combustion," Progress in Energy and Combustion Science, vol. 12, no. 1, pp. 25-41, 1986.

[7] J. Tsou, L. Pinard, P. Magnoux, J. L. Figueiredo, and M. Guisnet, "Catalytic oxidation of volatile organic compounds (VOCs) Oxidation of o-xylene over Pt/HBEA catalysts," Applied Catalysis B, vol. 46, no. 2, pp. 371-379, 2003.

[8] E. Porcel, S. Liehn, H. Remita et al., "Platinum nanoparticles: a promising material for future cancer therapy?" Nanotechnology, vol. 21, no. 8, Article ID 085103, 2010.

[9] M. Xiaofei, L. Liu, N. Aronhime, and M. R. Zachariah, "Ignition catalyzed by unsupported metal nanoparticles," Energy \& Fuels, vol. 25, no. 9, pp. 3925-3933, 2011.

[10] M. A. Asoro, D. Kovar, Y. Shao-Horn, L. F. Allard, and P. J. Ferreira, "Coalescence and sintering of Pt nanoparticles: in situ observation by aberration-corrected HAADF STEM," Nanotechnology, vol. 21, no. 2, p. 025701, 2010.

[11] I. E. Beck, V. I. Bukhtiyarov, I. Y. Pakharukov, V. I. Zaikovsky, V. V. Kriventsov, and V. N. Parmon, "Platinum nanoparticles on $\mathrm{Al}_{2} \mathrm{O}_{3}$ : correlation between the particle size and activity in total methane oxidation," Journal of Catalysis, vol. 268, no. 1, pp. 60-67, 2009.

[12] S. Mostafa, F. Behafarid, J. R. Croy et al., "Shape-dependent catalytic properties of Pt nanoparticles," Journal of the American Chemical Society, vol. 132, no. 44, pp. 15714-15719, 2010.

[13] G. Guisbiers, G. Abudukelimu, and D. Hourlier, "Sizedependent catalytic and melting properties of platinumpalladium nanoparticles," Nanoscale Research Letters, vol. 6, no. 1, p. 396, 2011.

[14] M. Broussely and G. Archdale, "Li-ion batteries and portable power source prospects for the next 5-10 years," Journal of Power Sources, vol. 136, no. 1, pp. 386-394, 2004.

[15] A. M. Karim, J. A. Federici, and D. G. Vlachos, "Portable power production from methanol in an integrated thermoeletric/microreactor system," Journal of Power Sources, vol. 179, no. 1, pp. 113-120, 2008.

[16] J. A. Federici, D. G. Norton, T. Brüggemann, K. W. Voit, E. D. Wetzel, and D. G. Vlachos, "Catalytic microcombustors with integrated thermoelectric elements for portable power production," Journal of Power Sources, vol. 161, no. 2, pp. 14691478, 2006.

[17] J. T. Wiswall, M. S. Wooldridge, and H. G. Im, "An experimental study of the effects of platinum on methane/air and propane/air mixtures in a stagnation point flow reactor," Journal of Heat Transfer, vol. 131, no. 11, pp. 1-8, 2009.

[18] J. D. Holladay, E. O. Jones, M. Phelps, and J. Hu, "Microfuel processor for use in a miniature power supply," Journal of Power Sources, vol. 108, no. 1-2, pp. 21-27, 2002.

[19] A. C. Fernandez-Pello, "Micropower generation using combustion: Issues and approaches," Proceedings of the Combustion Institute, vol. 29, no. 1, pp. 883-898, 2002.

[20] J. A. Federici and D. G. Vlachos, "A computational fluid dynamics study of propane/air microflame stability in a heat 
recirculation reactor," Combustion and Flame, vol. 153, no. 12, pp. 258-269, 2008.

[21] K. Bijjula and D. Vlachos, "Catalytic ignition and autothermal combustion of JP- 8 and its surrogates over a $\mathrm{Pt} / \gamma-\mathrm{Al}_{2} \mathrm{O}_{3}$ catalyst," Proceedings of the Combustion Institute, vol. 33, pp. 1801-1807, 2011.

[22] J. Ahn, C. Eastwood, L. Sitzki, and P. D. Ronney, "Gas-phase and catalytic combustion in heat-recirculating burners," in Proceedings of the 30th International Symposium on Combustion, vol. 30, pp. 2463-2472, July 2004.

[23] M. J. Lee and N. I. Kim, "Experiment on the effect of Ptcatalyst on the characteristics of a small heat-regenerative CH4-air premixed combustor," Applied Energy, vol. 87, no. 11, pp. 3409-3416, 2010.

[24] Z. Hu, V. Boiadjiev, and T. Thundat, "Nanocatalytic spontaneous ignition and self-supporting room-temperature combustion," Energy and Fuels, vol. 19, no. 3, pp. 855-858, 2005.

[25] Y. Ma, C. Ricciuti, T. Miller, J. Kadlowec, and H. Pearlman, "Enhanced catalytic combustion using sub-micrometer and nano-size platinum particles," Energy and Fuels, vol. 22, no. 6, pp. 3695-3700, 2008.

[26] K. Dick, T. Dhanasekaran, Z. Zhang, and D. Meisel, "Sizedependent melting of silica-encapsulated gold nanoparticles," Journal of the American Chemical Society, vol. 124, no. 10, pp. 2312-2317, 2002.

[27] P. Forzatti and L. Lietti, "Catalyst deactivation," Catalysis Today, vol. 52, no. 2-3, pp. 165-181, 1999.

[28] T. Sanders, P. Papas, and G. Veser, "Supported nanocomposite catalysts for high-temperature partial oxidation of methane," Chemical Engineering Journal, vol. 142, no. 1, pp. 122-132, 2008.

[29] T. Mitsui, T. Matsui, H. Miyata et al., "Formation of layered $\mathrm{Al}_{2} \mathrm{O}_{3}$ and its inhibitory effect on the sintering of supported platinum particles," Applied Catalysis A, vol. 348, no. 1, pp. 121-128, 2008.

[30] F. Bonet, V. Delmas, S. Grugeon, R. H. Urbina, and P.-Y. Silvert, "Sythesis of monodisperse $\mathrm{Au}, \mathrm{Pt}, \mathrm{Pd}, \mathrm{Ru}$ and $\mathrm{Ir}$ nanoparticles in glycol," Acta Metallurgica, vol. 11, no. 8, pp. 1277-1284, 2000.

[31] S. D. Bakrania, T. A. Miller, C. Perez, and M. S. Wooldridge, "Combustion of multiphase reactants for the synthesis of nanocomposite materials," Combustion and Flame, vol. 148, no. 1-2, pp. 76-87, 2007.

[32] J. Li, J. Zhang, Z. Lei, and B. Chen, "Pd-Co coating onto cordierite monoliths as structured catalysts for methane catalytic combustion," Energy and Fuels, vol. 26, no. 1, pp. 443450, 2012. 

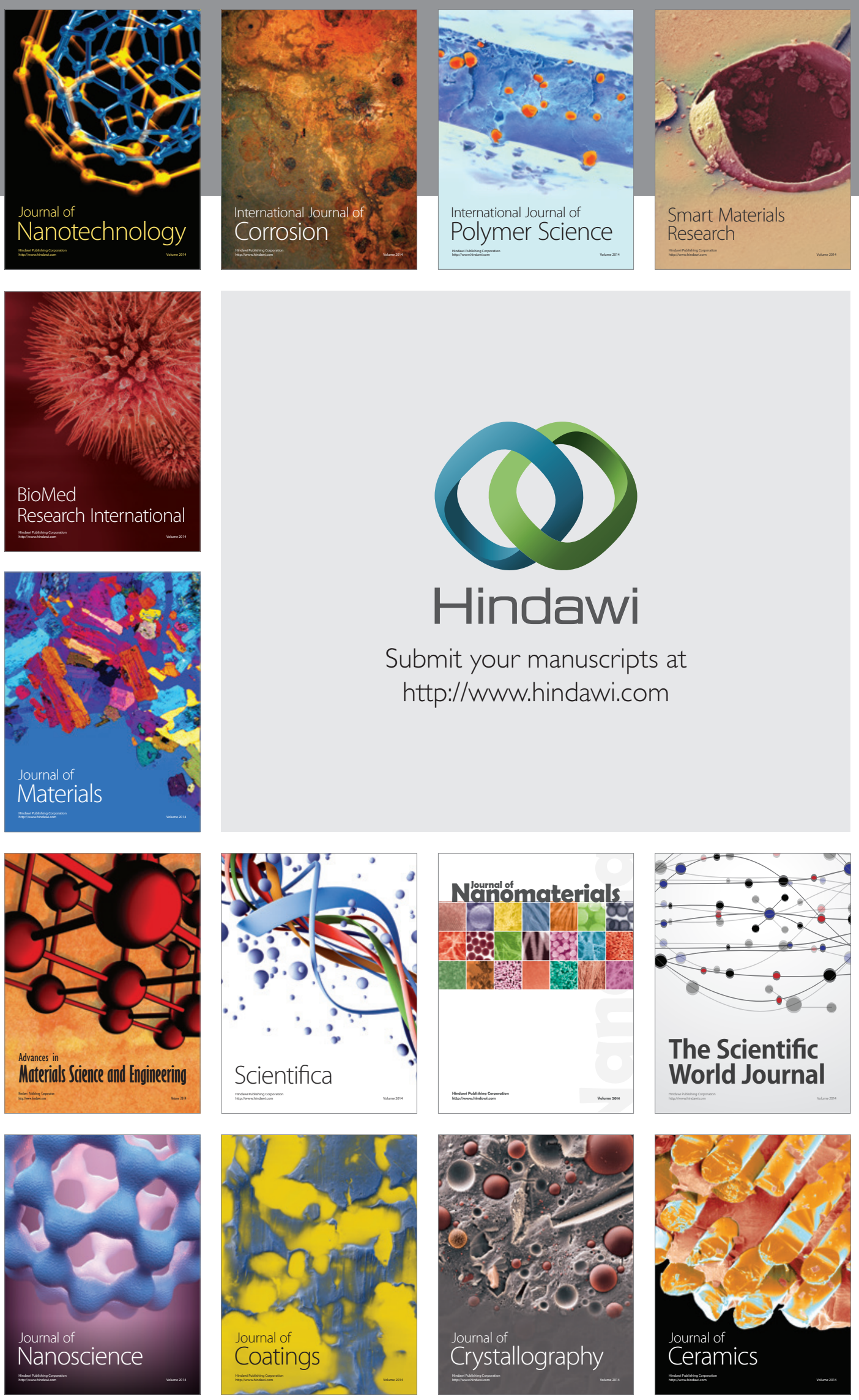

The Scientific World Journal

Submit your manuscripts at

http://www.hindawi.com

\section{World Journal}

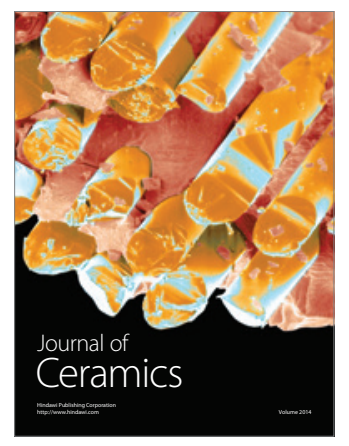

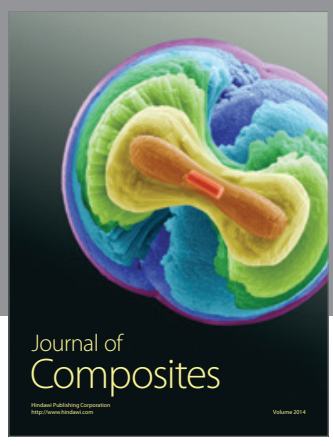
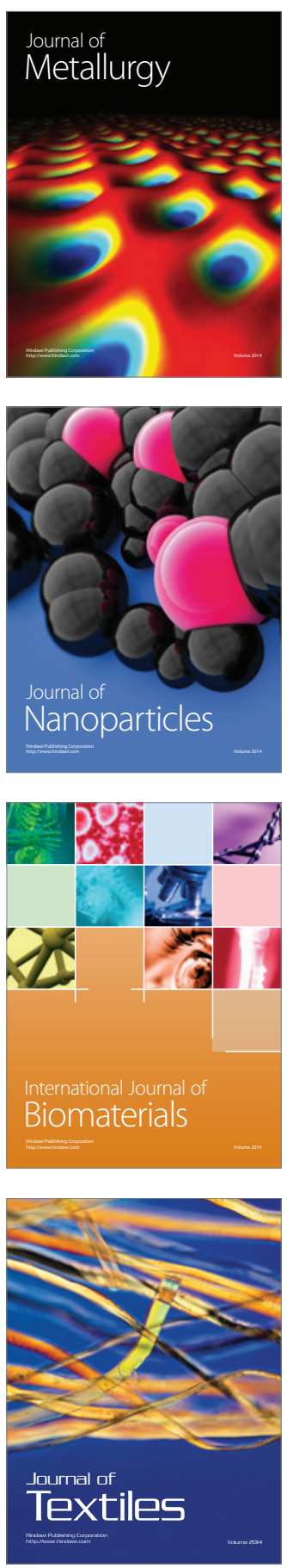